\title{
Analysis of Fgm Beam under a Udl Load
}

\author{
S.Tharaknath. M.Tech ${ }^{1}$, S.Govindaraji ${ }^{2}$, T.Anbu ${ }^{3}$, \\ G.purushothaman ${ }^{4}$ C.kannadhasan ${ }^{5}$ \\ (Asst professor, Priyadarshini Engineering Collegel Anna university, India) \\ ${ }^{2,3,4,5}$ (Engineering design, Priyadarshini Engineering College/ Anna University, India)
}

\begin{abstract}
Static analysis of a functionally graded (FG) simply-supported beam subjected to a uniformly distributed load has been investigated by using Ritz method within the framework of Timoshenko and the higher order shear deformation beam theories. The material properties of the beam vary continuously in the thickness direction according to the power-law form. Trial functions denoting the transverse, the axial deflections and the rotation of the cross-sections of the beam are expressed in trigonometric functions. In this study, the effect of various material distributions on the displacements and the stresses of the beam are examined. Numerical results indicate that stress distributions in FG beams are very different from those in isotropic beams.
\end{abstract}

Keywords: Beams, functionally graded materials, Timoshenko beam theory, the higher order shear deformation theory,

\section{Introduction}

In material sciences, a functionally graded material (FGM) is a type of material whose composition is designed to change continuously within the solid. The concept is to make a composite material by varying the microstructure from one material to another material with a specific gradient. This enables the material to have good specifications of both materials. If it is for thermal or corrosive resistance or malleability and toughness, both strengths of the material may be used to avoid corrosion, fatigue, fracture and stress corrosion cracking. The transition between the two materials can usually be approximated by means of a power series. The aircraft and aerospace industry and the computer circuit industry are very interested in the possibility of materials that can withstand very high thermal gradients. This is normally achieved by using a ceramic layer connected with a metallic layer. The concept of FGM was first considered in Japan in 1984 during a space plane project. The FGM materials can be designed for specific applications. For example, thermal barrier coatings for turbine blades (electricity production), armor protection for military applications, fusion energy devices, biomedical materials including bone and dental implants, space/aerospace industries, automotive applications, etc.

\section{Numerical Calculation}

Maximum non-dimensional deflections of the beam are presented for various values of power-law exponent and for $\mathrm{L} / \mathrm{h}=4,16$. It is seen from Table 1 that as the value of the power-law exponent increases, the deflections of the beam decrease. This is due to the fact that an increase in the power-law exponent yields a decrease in the bending rigidity of the beam, as also seen by inspecting Fig. 2. As would be expected (FGM) of the beam is composed of Aluminum ( $\mathrm{Al} ; 70 \mathrm{GPa}, \mathrm{u}=0.3 \mathrm{~m}$ ) and Zirconia ( $2 \mathrm{ZrO} ; 200 \mathrm{GPa}, \mathrm{u}=0.3 \mathrm{c}$ ) and its properties changes through the thickness of the beam according to the power-law. The bottom surface of the FG beam is pure Zirconia, whereas the top surface of the beam is pure Aluminum.. Note also that the deflections of TBT and HOSDT are very close to each other. As is known, shear deformation effect plays an important role on the responses of the short beams, and the displacements of the shear deformable beam theories are larger than those of Euler-Bernoulli beam theory. This effect is clearly seen for full metal beam with $\mathrm{L} / \mathrm{h}=4$.

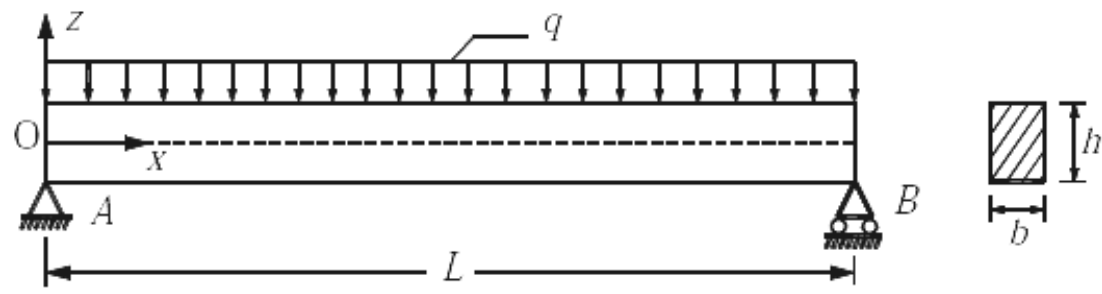

Fig-1 beam

\section{Timoshenko Beam Theory (Tbt)}

If the shear modulus of the beam material approaches infinity and thus the beam become rigid in shear and in rotational inertia effects are neglected 
A functionally graded simply-supported beam of length L, width $\mathrm{b}$, thickness $\mathrm{h}$, with coordinate system ( $\mathrm{x}$ y $\mathrm{z}$ ) having the origin $\mathrm{O}$. The beam is subjected to a uniformly distributed load - $\mathrm{q}$.

In this study, it is assumed that the FG beam is made of metal, and the effective material properties of the FG beam, i.e., Young's modulus E, Poisson's ratio u and shear modulus G vary continuously in the thickness direction ( $\mathrm{z}$ axis direction) according to power-law form introduced by - [17] Where $\mathrm{k}$ is the nonnegative variable parameter (power-law exponent) which dictates the material variation profile through the thickness of the beam, $\mathrm{m}$ and stand for metal and constituents respectively.

$\mathrm{z}=\mathrm{h} / 2$

$\mathrm{Ez}=\mathrm{Em}[\mathrm{Z} / \mathrm{h}+1 / 2]^{\wedge} \mathrm{k}+\mathrm{Em} \quad-\quad$ [ young`s modulus $]$

$\mathrm{Uz}=\mathrm{Um}[\mathrm{Z} / \mathrm{h}+1 / 2]^{\wedge} \mathrm{k}+\mathrm{Um} \quad-\quad$ [Poisson ratio]

$\mathrm{Gz}=\mathrm{Ez} / 2[1+\mathrm{Uz}] \quad$ [Shear modulus]

where $0 \mathrm{u}$ and $0 \mathrm{w}$ are the axial and the transverse displacement of any point on the neutral axis, $\mathrm{f}$ is the rotation of the cross-sections, $\mathrm{a}=4 /(3 \mathrm{~h} 2)$, and, $\mathrm{x}$ indicates the derivative with respect to $\mathrm{x}$.

As it is known, when some expressions satisfying kinematic boundary conditions are selected for ( $\mathrm{x}$ ) 0 $\mathrm{w} x,(\mathrm{x}) 0 \mathrm{u} \mathrm{x}$ and $\mathrm{f}(\mathrm{x})$ then by using the principle of the minimum potential energy, the natural (dynamic) boundary conditions are also satisfied. The displacements ( $\mathrm{x}$ ) $0 \mathrm{w},(\mathrm{x}) 0 \mathrm{u}$ and rotation $\mathrm{f}(\mathrm{x})$ are expanded by the following series which satisfy the kinematic boundary conditions.

\section{Elastic Properties Of Fgms:}

The longitudinal stiffness of a composite can be obtained from the rule or law of mixture which is represented by the relationship given below.

$\mathrm{Em}=\mathrm{E}_{\mathrm{f}} \mathrm{V}_{\mathrm{f}}+\mathrm{E}_{\mathrm{m}} \mathrm{V}_{\mathrm{m}}$

Based on the higher order shear deformation theory, the axial displacement, $\mathrm{x} u$, and the transverse displacement of any point of the beam, $\mathrm{z} u$.

$\mathrm{U}_{\mathrm{x} x} \mathrm{u}[\mathrm{x}, \mathrm{z}]=\mathrm{u} \mathrm{x}+\mathrm{zf} \mathrm{x}-\mathrm{a} \mathrm{z} \mathrm{w} \mathrm{x}+\mathrm{f} \mathrm{x} 0, \mathrm{z} \mathrm{u}[\mathrm{x}, \mathrm{z}]=\mathrm{w} \mathrm{x} \quad-[17]$

where $\mathrm{xx}$ and $\mathrm{xz}$ are the normal and the shear strain, respectively. By assuming that the material of FGM beam obeys Hooke's law, the stresses in the beam become

( $\epsilon)_{\mathrm{xx}} \mathrm{Xx}_{\mathrm{s}}=\mathrm{E} \mathrm{z} \mathrm{e}$

( $\epsilon)_{\mathrm{xz}} \mathrm{xz} \mathrm{t}=\mathrm{G}$

The axial and the transverse displacements of the beam are normalized by the static deflection,

$\mathrm{W}_{\text {static }}=5 \mathrm{qL}^{4} / 384 \mathrm{E}$ I under the uniformly distributed load.

The axial normal stresses, $\square_{\mathrm{xx}}$ are calculated at the midpoint of the beam ( $\mathrm{x}=\mathrm{L} / 2$ )

And the shear stresses, are evaluated at the left support of the beam $(\mathrm{x}=0)$

And the normal and the shear stresses are normalized by

$\left[\square_{\mathrm{xx}}, \square \mathrm{xz}\right]=\left[\square_{\mathrm{xx}} \mathrm{A} / \mathrm{qL}, \square \mathrm{xz} \mathrm{A} / \mathrm{qL}\right]$

Elastic Properties of FGMs

\section{$\mathrm{E}=\mathrm{Em}+\mathrm{Vm}$}

The in-plane shear modulus can be obtained from a similar model to that used for obtaining transverse stiffness which results in the in-plane shear modulus expression as given below.

$$
1 / \mathrm{u}=\mathrm{Vm} / \mathrm{Um}
$$

The Poisson's ratio of a composite is given below

$$
\mathrm{U}=\mathrm{Vm}+\mathrm{Vm}
$$

\section{Strength Properties Of Fgms}

The longitudinal tensile strength of FGMs is given below.

$$
\mathrm{Xt}=\mathrm{Xmt}[\mathrm{Vm}+\mathrm{Em}]
$$

The longitudinal compressive strength of FGMs for $\mathrm{V}_{\mathrm{f}}<0.5$ is given below

The transverse tensile strength of FGMs is given below

$$
\mathrm{Xc}=2 \mathrm{Vm}[\mathrm{Em}] \mathrm{Vm} / 3(1-\mathrm{Vm})
$$

$$
\mathrm{Yt}=\mathrm{Xmt}-\mathrm{Rm} / \mathrm{Km}
$$

The transverse compressive strength of FGMs is given below.

$$
\mathrm{Yc}=\mathrm{Xmc}+\mathrm{Rm} / \mathrm{Km}
$$

\section{Non-Dimensional Transverse And The Axial Displacements}

Figs. 2 and 3 show the non-dimensional transverse and the axial displacements along the length of the beam, respectively. As stated before, when the power-law exponent is increased, the displacements of the FG beam are decreased. The axial displacements of the full metal and full ceramic beams are zero and coincide with 
each other. Because, in full metal and the full ceramic beams (isotropic beams), there is no coupling between the bending and the stretching, namely $\mathrm{xx} \mathrm{B}=\mathrm{E}=0$. In contrast to transverse displacements, as seen from Fig. 2, firstly the axial displacements increase with the increase in the power-law exponent, and then decrease with further increase in the power-law exponent. It is also to be noted that as the power-law exponent increases, the composition of the FG beam approaches to the composition of the full ceramic beam.
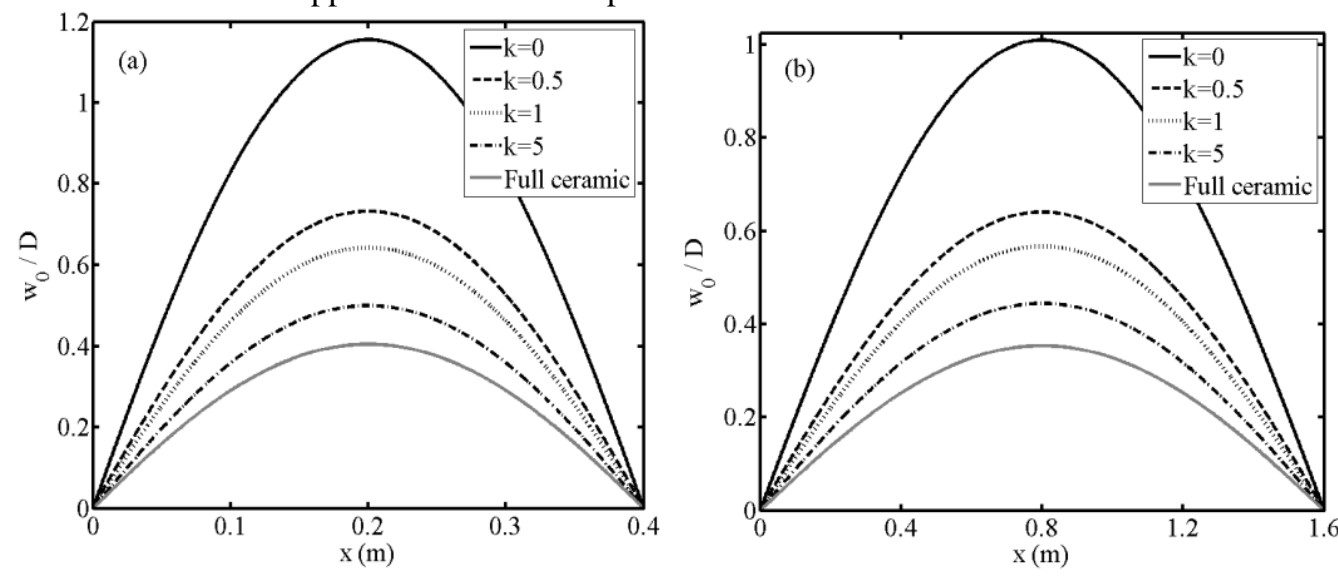

Fig.2. Non-dimensional transverse displacements along the length of the beam for a) $\mathrm{L} / \mathrm{h} \square .4 \mathrm{~b}) \mathrm{L} / \mathrm{h} \square \mathbf{1 6}$.
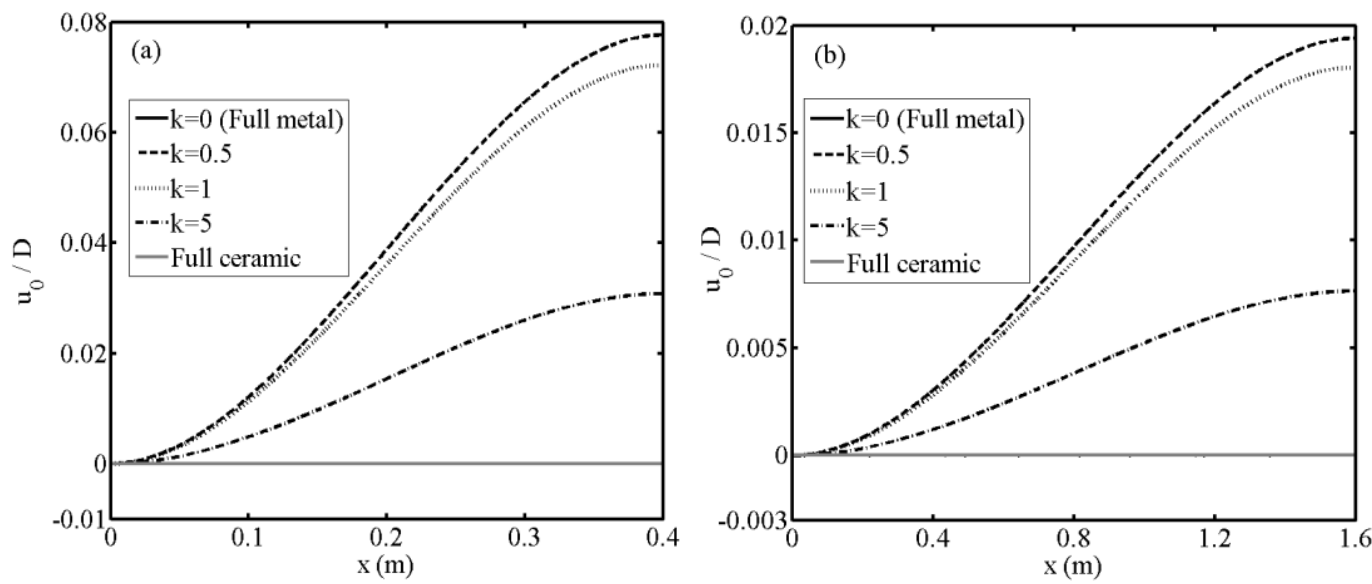

Fig.3. Non-dimensional axial displacements along the length of the beam for a) $L / h \square .4$ b) $\mathbf{L} / \mathbf{h} \square \mathbf{1 6}$
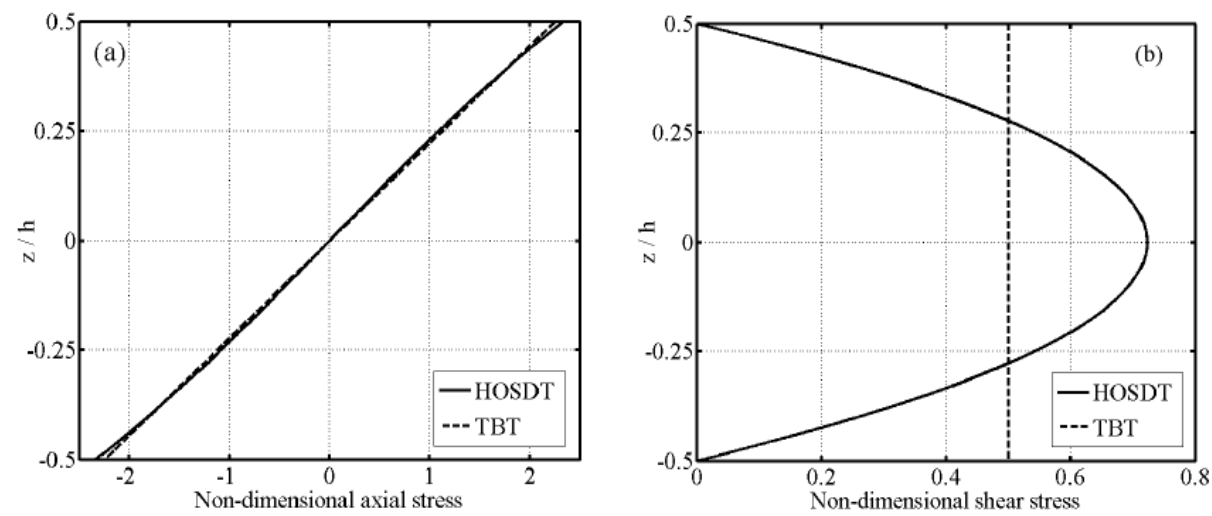

Fig.4. Non-dimensional axial and shear stress distributions of the metal beam for $L / h=3$

Fig. 4 displays the non-dimensional axial and the shear stress distributions of the full metal beam along the thickness of the beam. As seen from Fig. 3a, the normal stress distribution is not linear for HOSDT represented by black solid line. Also, the magnitude of the axial stresses of HOSDT is a little larger than those of TBT. The shear stress distribution is parabolic and the zero stress condition on the upper and the lower side of the cross-section is satisfied for HOSDT. Furthermore, the constant shear stress assumption of TBT is clearly 
seen from Fig. 3b. Fig. 4 shows the non-dimensional axial normal stress distributions of HOSDT for various values of power-law exponent. The most significant aspect of this figure is that the axial normal stress distributions of FG beams are much more different from those in isotropic beams. Although the magnitude of the axial compressive and the axial tensile stresses have the same magnitude in full metal and full ceramic beams (isotropic beams), the magnitude of the tensile stresses are greater than the magnitude of the compressive stresses in FG beams. The value of the axial stresses is not zero at the mid-plane of the FG beam. This indicates that the neutral plane of the beam moves towards the lower side of the beam for the FG beam. This is due to the variation of the modulus of elasticity through the thickness of the FG beam.
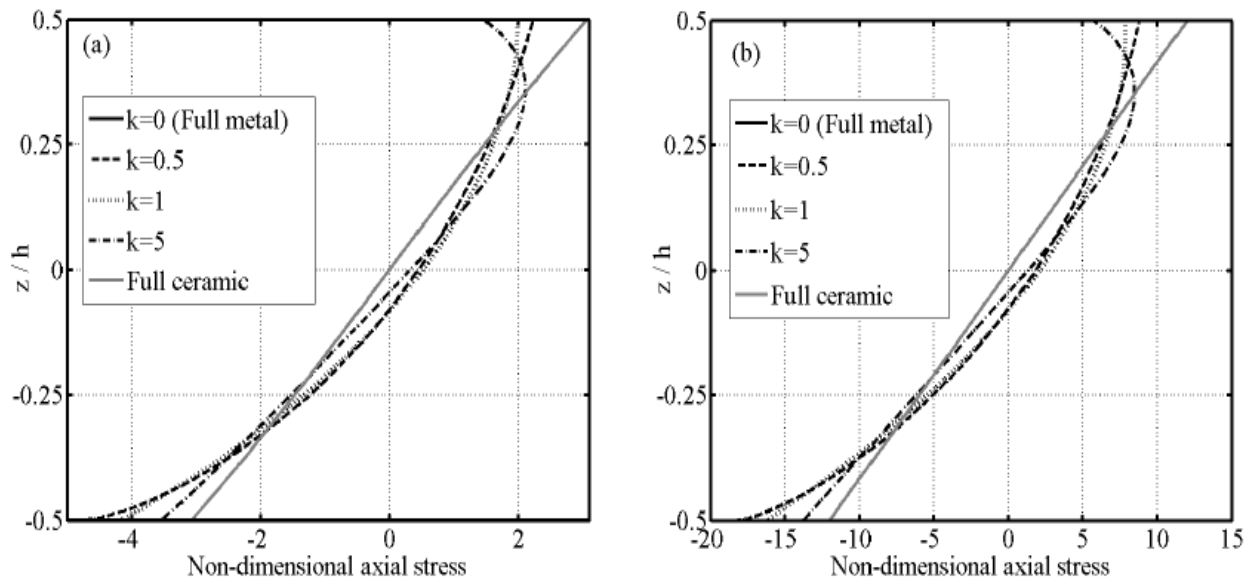

Fig. 5. Non-dimensional axial stress distributions for various values of power-law exponent, a)

$$
\mathrm{L} / \mathrm{h}=\mathbf{4} \mathrm{b}) \mathrm{L} / \mathrm{h}=16
$$

\section{Conclusion}

Static analysis of an FG simply-supported beam subjected to a uniformly distributed load is investigated within the framework of HOSDT and TBT by using Ritz Method. Trial functions denoting the transverse, the axial deflections and the rotation of the cross-sections of the beam are expressed in trigonometric functions. The material properties of the beam vary continuously in the thickness direction according to the power-law form. Numerical results show that the variation of the modulus of elasticity plays a major role on the stress distributions and the displacements of the FG beam. Also, in the design of structures, by choosing a suitable power-law exponent, the material properties of the FG beam can be tailored to meet the desired goals of minimizing stresses and displacements in a beam-type structure.

\section{References}

[1]. Sankar B.V., An elasticity solution for functionally graded beams. Composites Sciences and Technology, 61(5), 689-696, 2001.

[2]. Chakraborty A., Gopalakrishnan S, Reddy J.N., A new beam finite element for the analysis of functionally graded materials. International Journal of Mechanical Sciences, 45(3), 519-539, 2003.

[3]. Chakraborty A., Gopalakrishnan S., A spectrally formulated finite element for wave propagation analysis in functionally graded beams. International Journal of Solids and Structures, 40(10), 2421-2448, 2003.

[4]. Aydogdu M., Taskin V., Free vibration analysis of functionally graded beams with simply supported edges. Materials \& Design, 28(5), 1651-1656, 2007.11

[5]. Zhong Z., Yu T., Analytical solution of a cantilever functionally graded beam. Composites Sciences and Technology, 67(3-4), 481488, 2007.

[6]. Ying J., Lü C.F., Chen W.Q., Two-dimensional elasticity solutions for functionally graded beams resting on elastic foundations. Composite Structures, 84(3), 209-219, 2008.

[7]. Kapuria S., Bhattacharyya M., Kumar A.N., Bending and free vibration response of layered functionally graded beams: A theoretical model and its experimental validation. Composite Structures, 82(3), 390-402, 2008

[8]. Yang J., Chen Y., Free vibration and buckling analyses of functionally graded beams with edge cracks. Composite Structures, 83(1), 48-60, 2008.

[9]. Li X.F., A unified approach for analyzing static and dynamic behaviors of functionally graded Timoshenko and Euler-Bernoulli beams. Journal of Sound and Vibration, 318(4-5), 1210-1229, 2008.

[10]. Yang J., Chen Y., Xiang Y., Jia X.L., Free and forced vibration of cracked inhomogeneous beams under an axial force and a moving load. Journal of Sound Vibration, 312(1-2), 166-181, 2008. 